\title{
Epidemiology of cerebral palsy in England and Scotland, 1984-9
}

\author{
P O D Pharoah, T Cooke, M A Johnson, R King, L Mutch
}

\begin{abstract}
Aims-To report on the epidemiology of cerebral palsy in England and Scotland, to provide information on the prevalence of cerebral palsy and the severity of the disability or any co-morbidity.
\end{abstract}

Methods-Cerebral palsy registers were compiled from multiple sources of ascertainment covering all of Scotland and the counties of Merseyside, Cheshire, Berkshire, Buckinghamshire, Northamptonshire and Oxfordshire in England. All cases of cerebral palsy born in 1984 to 1989 , to mothers resident in the area, were included. Denominator number of live births and neonatal deaths for determining birthweight specific prevalence were obtained from birth and death registrations. Learning, manual, and ambulatory disabilities were graded for severity. Any co-existing sensory (hearing or visual) morbidity was also graded for severity.

Results-There were 789411 live births in 1984-9, with 3651 neonatal deaths (neonatal mortality 4.6 per 1000 live births) and 1649 cases of cerebral palsy-a cerebral palsy prevalence of 2.1 per 1000 neonatal survivors. The birthweight specific cerebral palsy prevalence ranged from 1.1 per 1000 neonatal survivors in infants weighing $\geqslant 2500 \mathrm{~g}$ to 78.1 in infants weighing $<1000 \mathrm{~g}$. There was no significant time trend in prevalence of cerebral palsy in any of the birthweight groups, in contrast to the fall in neonatal mortality observed in all birthweight groups. Of the 1649 cases of cerebral palsy, 550 (33.4\%) had severe ambulatory disability (no independent walking), $390(23.7 \%)$ had severe manual disability (incapable of feeding or dressing unaided), $381(23.1 \%)$ had severe learning disability (IQ <50), $146(8.9 \%)$ had severe visual disability (vision $<6 / 60$ in the better eye) and 12 had severe hearing disability (>70 dB loss).

Conclusions-Registers fill an important gap left by the lack of routine data on the prevalence of disability in children. The ability to record trends in the prevalence and the severity of the disability should inform those who have responsibility for providing services for children with disabilities.

(Arch Dis Child Fetal Neonatal Ed 1998;79:F21-F25)

Keywords: cerebral palsy; disability; registers; England; Scotland
Information on the prevalence and epidemiology of disability in children is not available from routine health service data systems. The Mersey Region Cerebral Palsy Register, the Oxford Region Register of Early Childhood Impairments, and the Scottish Register of Children with a Motor Deficit of Central Origin were developed with the intention of filling this gap in the routine data systems. ${ }^{1}$ The impetus for this came from the technological advances in neonatal intensive care and the improving prognosis for survival of low birthweight infants ${ }^{23}$ among whom there was an increased prevalence of cerebral palsy. Even infants weighing $<1000 \mathrm{~g}$ at birth are now more likely to survive the neonatal period. ${ }^{4}$ Associated with improving survival among progressively lower birthweight infants there have been reports from different countries of increasing birth prevalence rates of cerebral palsy particularly among low birthweight infants. ${ }^{5-8}$

The overlapping time period covered by the Mersey, Oxford, and Scottish registers has allowed the time trends and epidemiology of cerebral palsy to be examined, including the severity of the motor disability and the prevalence and severity of co-disabilities of cognition, vision, and hearing, that covers the total population of births in Scotland and over 10\% of births in England from 1984 to 1989.

\section{Methods}

The Mersey Register covers the counties of Merseyside and Cheshire, and includes all children with cerebral palsy born to mothers resident in those counties at the time of the child's birth. The Oxford register similarly covers the counties of Berkshire, Buckinghamshire, Northamptonshire and Oxfordshire. ${ }^{9}$ The Scottish register is national, covering the whole of Scotland. ${ }^{10}$

The ascertainment of cases for the Mersey and Oxford registers was abstracted from several sources of data including: assessment centres, special schools, "handicap" and special needs registers; the York register of children claiming Family Disability Allowance; the Office for National Statistics for infants in whom cerebral palsy was recorded as a cause of death; and from regular reporting from physiotherapy departments, consultant and community paediatricians, and paediatric neurologists.

In Scotland case finding relied on the routine health services reporting of cases. This was usually by community paediatricians, particularly those involved in recording children as having special needs, those dealing with special schools, by some assessment centres and by one paediatric neurology clinic. Unlike the Mersey and Oxford regions, a dedicated 
Table 1 Birthweight specific trends in cerebral palsy prevalence*

\begin{tabular}{|c|c|c|c|c|c|c|}
\hline Year & $\begin{array}{l}\text { Number of live } \\
\text { births }\end{array}$ & $\begin{array}{l}\text { Number of neonatal } \\
\text { deaths }\end{array}$ & $\begin{array}{l}\text { Neonatal mortality rate per } \\
1000 \text { livebirths ( } 95 \% \text { CI) }\end{array}$ & $\begin{array}{l}\text { Number of } \\
\text { survivors }\end{array}$ & $\begin{array}{l}\text { Number with cerebral } \\
\text { palsy }\end{array}$ & $\begin{array}{l}\text { Prevalence of cerebral palsy per } \\
1000 \text { neonatal survivors }(95 \% \text { CI) }\end{array}$ \\
\hline \multicolumn{7}{|c|}{ Birthweight $<1000 \mathrm{~g}$} \\
\hline 1984 & 367 & 193 & $527.3(474.8-579.4)$ & 174 & 9 & $51.7(23.9-95.9)$ \\
\hline 1985 & 361 & 205 & $567.9(515.0-619.6)$ & 156 & 10 & $64.1(31.2-114.7)$ \\
\hline 1986 & 397 & 208 & $523.8(473.5-574.0)$ & 189 & 18 & $95.2(57.4-146.3)$ \\
\hline 1987 & 403 & 197 & $488.8(439.0-538.8)$ & 206 & 21 & $101.9(64.2-151.6)$ \\
\hline 1988 & 391 & 175 & $447.6(397.6-498.4)$ & 216 & 14 & $64.8(35.9-106.4)$ \\
\hline 1989 & 385 & 174 & $451.9(401.5-503.2)$ & 211 & 18 & $85.3(51.3-131.5)$ \\
\hline $1984-89$ & 2304 & 1152 & $500.0(479.4-520.6)$ & 1152 & 90 & $78.1(63.3-95.2)$ \\
\hline \multicolumn{7}{|c|}{ Birthweight $1000-1499 \mathrm{~g}$} \\
\hline 1984 & 760 & 115 & $151.3(126.6-178.8)$ & 645 & 41 & $63.6(46.0-85.2)$ \\
\hline 1985 & 752 & 109 & $144.9(120.6-172.2)$ & 643 & 38 & $59.1(42.2-80.2)$ \\
\hline 1986 & 756 & 97 & $128.3(105.3-154.3)$ & 659 & 44 & $66.8(48.9-88.6)$ \\
\hline 1987 & 814 & 108 & $132.7(110.1-157.9)$ & 706 & 47 & $66.6(49.3-87.5)$ \\
\hline 1988 & 839 & 117 & $139.5(116.7-168.8)$ & 722 & 44 & $60.9(44.6-81.0)$ \\
\hline 1989 & 781 & 93 & $119.1(97.2-143.9)$ & 688 & 53 & $77.0(58.2-99.6)$ \\
\hline $1984-89$ & 4702 & 639 & $135.9(126.2-146.0)$ & 4063 & 267 & $65.7(58.3-73.8)$ \\
\hline \multicolumn{7}{|c|}{ Birthweight $1500-2499 \mathrm{~g}$} \\
\hline 1984 & 7133 & 153 & $21.5(18.2-25.1)$ & 6980 & 67 & $9.6(7.4-12.2)$ \\
\hline 1985 & 7524 & 129 & $17.1(14.3-20.3)$ & 7395 & 74 & $10.0(7.9-12.5)$ \\
\hline 1986 & 7490 & 112 & $15.0(12.3-18.0)$ & 7378 & 80 & $10.8(8.6-13.5)$ \\
\hline 1987 & 7514 & 102 & $13.6(11.1-16.5)$ & 7412 & 75 & $10.1(8.0-12.7)$ \\
\hline 1988 & 7360 & 106 & $14.4(11.8-17.4)$ & 7254 & 84 & $11.6(9.2-14.3)$ \\
\hline 1989 & 7156 & 124 & $17.3(14.4-20.6)$ & 7032 & 63 & $9.0(6.9-11.4)$ \\
\hline $1984-89$ & 44177 & 726 & $16.4(15.3-17.7)$ & 43451 & 443 & $10.2(9.2-11.2)$ \\
\hline \multicolumn{7}{|c|}{ Birthweight $\geqslant 2500 \mathrm{~g}$} \\
\hline 1984 & 119767 & 209 & $1.7(1.5-2.0)$ & 119558 & 140 & $1.2(1.0-1.4)$ \\
\hline 1985 & 122199 & 199 & $1.6(1.4-1.9)$ & 122000 & 154 & $1.3(1.1-1.5)$ \\
\hline 1986 & 122167 & 209 & $1.7(1.5-2.0)$ & 121958 & 151 & $1.2(1.0-1.5)$ \\
\hline 1987 & 123887 & 182 & $1.5(1.3-1.7)$ & 123705 & 149 & $1.2(1.0-1.4)$ \\
\hline 1988 & 126284 & 182 & $1.4(1.2-1.7)$ & 126102 & 128 & $1.0(0.8-1.2)$ \\
\hline 1989 & 120761 & 150 & $1.2(1.1-1.4)$ & 120611 & 118 & $1.0(0.8-1.2)$ \\
\hline $1984-89$ & 735065 & 1131 & $1.5(1.4-1.6)$ & 733934 & 840 & $1.1(1.1-1.2)$ \\
\hline
\end{tabular}

^There were nine children for whom birthweight was not recorded.

research assistant did not maintain the register and any difference in the completeness of ascertainment could be attributed to this. Deaths with a mention of cerebral palsy were reported from the Office of the Registrar General for Scotland.

Denominator numbers of live births and neonatal deaths for determining the birthweight specific prevalence of cerebral palsy were obtained from the legally required birth and death registrations.

Four clinical types of cerebral palsy were recognised: hemiplegia; diplegia; quadriplegia; and "other," which included the ataxic, dyskinetic, hypotonic and mixed varieties of the syndrome. Assignment to a clinical category in Oxford and Scotland was made from the reporting form which was based on the standard format for recording motor deficit of central origin. ${ }^{11}$ In Mersey the clinical type of cerebral palsy was that recorded by the paediatrician in the case notes and no attempt was made to standardise the recording of signs.

Levels of functional disability were categorised for ambulatory, manual, learning, hearing and visual disabilities. For the Mersey register, after a child was ascertained as having cerebral palsy, paediatric records were subsequently abstracted to obtain details of any functional disability.

Ambulatory disability was classified as "none" if fluent and stairs could be climbed without difficulty; "mild" if ambulation was limited and non-fluent, if there was difficulty in climbing stairs; "moderate" if there was obvious reduced mobility and/or the child required walking aids; and "severe" if there was no independent walking even with aids.
Manual disability was classified as "none" if there was no apparent problem; "mild" if the child had some difficulty using both hands together but could feed or dress unaided; "moderate" if feeding and dressing unaided could be done only with considerable difficulty and "severe" if the child was incapable of feeding or dressing unaided.

Various methods of assessment were used for ascertaining the IQ of the child. The IQ was used to categorise the level of learning disability and, if an assessment of IQ had been made on more than one occasion, the most recent assessment was used for analysis. For the Oxford cases, formal IQ assessments were not recorded but paediatricians were asked whether there was minor, moderate, or severe learning disability. In the Scottish register intellectual impairment was sometimes assessed using Griffiths developmental assessment ${ }^{12}$ and occasionally was determined as an IQ by a psychologist, but was often a general view based on observation of the child by the examining doctor or teacher, grading the children as mildly, moderately, or severely delayed. In Merseyside most children had had a formal assessment by a psychologist. The assumption was made that minor or no learning disability was equivalent to an IQ $>70$, moderate learning disability was equivalent to an IQ in the range 50 to 70 , and severe learning disability corresponded to an IQ $<50$.

Visual disability was classified as "mild" if vision was $>6 / 18$ in the better eye, "moderate" if $6 / 18$ to $6 / 60$ in the better eye, "severe" if $<6 / 60$ in the better eye or there was no useful vision. 
Table 2 Clinical type of cerebral palsy by birthweight group

\begin{tabular}{|c|c|c|c|c|c|}
\hline \multirow{2}{*}{$\begin{array}{l}\text { Type of cerebral } \\
\text { palsy }\end{array}$} & $<1000 \mathrm{~g}$ & $1000-1499 \mathrm{~g}$ & $1500-2499 \mathrm{~g}$ & $\geqslant 2500 \mathrm{~g}$ & ${ }^{\star}$ All birthweights \\
\hline & $n(\%)$ & $n(\%)$ & $n(\%)$ & $n(\%)$ & $n(\%)$ \\
\hline Hemiplegia & $24(26.7 \%)$ & $53(19.9 \%)$ & $88(19.9 \%)$ & $305(36.3 \%)$ & $470(28.5 \%)$ \\
\hline Diplegia & $14(15.6 \%)$ & $78(29.2 \%)$ & $117(26.4 \%)$ & $79(9.4 \%)$ & $289(17.5 \%)$ \\
\hline Quadriplegia & $31(34.4 \%)$ & $101(37.8 \%)$ & $165(37.2 \%)$ & $274(32.6 \%)$ & $575(34.9 \%)$ \\
\hline Other ${ }^{t}$ & $21(23.3 \%)$ & $35(13.1 \%)$ & $73(16.5 \%)$ & $182(21.7 \%)$ & $315(19.1 \%)$ \\
\hline All CP & $90(100 \%)$ & $267(100 \%)$ & $443(100 \%)$ & $840(100 \%)$ & $1649(100 \%)$ \\
\hline
\end{tabular}

$\chi^{2}, 9 \mathrm{DF}=121.9 ; \mathrm{p}<0.0001$.

"Includes nine cases in whom the birthweight was not recorded.

†Includes 20 cases with type of cerebral palsy not recorded.

Hearing loss was averaged across frequencies $0.5-4 \mathrm{kHz}$ and the disability classified as "mild" if hearing loss was 21-45 dB, "moderate" for a $45-70 \mathrm{~dB}$ loss, "severe" with a hearing loss $>70 \mathrm{~dB}$. Assessment of accurate hearing levels was often impossible in children with concomitant intellectual impairment.

The cases for whom disability levels were recorded as "not known" were predominantly those who had died before the level of disability could be assessed. Inevitably, this will be a biased group because it would contain a disproportionate number who were more severely disabled.

In spite of the differing methods of ascertainment of cases in the three regions and the minor differences in categorising the severity of the disabilities, the results were similar for each region and it was felt to be justified to combine the three datasets.

The statistical tests used were either the normal approximation to the binomial for the difference between two proportions, the $\chi^{2}$ test or the $\chi^{2}$ test for trend.

\section{Results}

During 1984-9, there were 196439 live births in the Mersey Region, 204250 in the Oxford Region, and 388722 in Scotland. The total live birth population covered by the three registers was therefore 789411 among which there were 3651 neonatal deaths and 1649 cases of cerebral palsy among the survivors, giving a neonatal mortality rate of 4.6 per 1000 live births and a cerebral palsy prevalence of 2.1 per 1000 neonatal survivors.

Of the total 1649 cases of cerebral palsy, 840 (50.9\%), 443 (26.9\%), $267(16.2 \%)$ and 90 $(5.5 \%)$ were of birthweights $(2500 \mathrm{~g}, 1500-$ 2499 g, 1000-1499 g and $<1000$ g, respectively. In nine cases the birthweight was not known.

Table 1 shows the birthweight specific trends in the prevalence of cerebral palsy. There was no discernible trend over this short period of time in any of the birthweight groups. In the lowest birthweight group ( $<1000 \mathrm{~g}$ ), an early rise was succeeded by a fall in prevalence but the small number of cases each year means that

Table 3 Severity of functional disability by birthweight group

\begin{tabular}{|c|c|c|c|c|c|}
\hline & $<1000 \mathrm{~g}$ & $1000-1499 \mathrm{~g}$ & $1500-2499 \mathrm{~g}$ & $\geqslant 2500 \mathrm{~g}$ & ${ }^{\star}$ All birthweights \\
\hline \multicolumn{6}{|c|}{ Ambulatory disability: } \\
\hline None & $5(5.6 \%)$ & $10(3.7 \%)$ & $21(4.7 \%)$ & $64(7.6 \%)$ & $102(6.2 \%)$ \\
\hline Mild & $30(33.3 \%)$ & $97(36.3 \%)$ & $162(36.6 \%)$ & $333(39.6 \%)$ & $624(37.8 \%)$ \\
\hline Moderate & $16(17.8 \%)$ & $64(24.0 \%)$ & $102(23.0 \%)$ & $144(17.1 \%)$ & $327(19.8 \%)$ \\
\hline Severe & $35(38.8 \%)$ & $90(33.7 \%)$ & $147(33.2 \%)$ & $275(32.7 \%)$ & $550(33.4 \%)$ \\
\hline Not known & $4(4.4 \%)$ & $6(2.2 \%)$ & $11(2.5 \%)$ & $24(2.9 \%)$ & $46(2.8 \%)$ \\
\hline Total & $90(100 \%)$ & $267(100 \%)$ & $443(100 \%)$ & $840(100 \%)$ & $1649(100 \%)$ \\
\hline \multicolumn{6}{|c|}{ Manual disability: } \\
\hline None & $15(16.7 \%)$ & $49(18.4 \%)$ & $78(17.6 \%)$ & $83(9.9 \%)$ & $226(13.7 \%)$ \\
\hline Mild & $30(33.3 \%)$ & $94(35.2 \%)$ & $150(33.9 \%)$ & $317(37.7 \%)$ & $593(36.0 \%)$ \\
\hline Moderate & $22(24.4 \%)$ & $70(26.2 \%)$ & $102(23.0 \%)$ & $187(22.3 \%)$ & $385(23.3 \%)$ \\
\hline Severe & $19(21.1 \%)$ & $46(17.2 \%)$ & $98(22.1 \%)$ & $226(26.9 \%)$ & $390(23.7 \%)$ \\
\hline Not known & $4(4.4 \%)$ & $8(3.0 \%)$ & $15(3.4 \%)$ & $27(3.2 \%)$ & $55(3.3 \%)$ \\
\hline Total & $90(100 \%)$ & $267(100 \%)$ & $443(100 \%)$ & $840(100 \%)$ & $1649(100 \%)$ \\
\hline \multicolumn{6}{|c|}{ Learning disability: } \\
\hline None/mild & $45(50.0 \%)$ & $157(58.8 \%)$ & $223(50.3 \%)$ & $413(49.2 \%)$ & $839(50.9 \%)$ \\
\hline Moderate & $16(17.8 \%)$ & $43(16.1 \%)$ & $72(16.3 \%)$ & $148(17.6 \%)$ & $283(17.2 \%)$ \\
\hline Severe & $18(20.0 \%)$ & $38(14.2 \%)$ & $81(18.3 \%)$ & $241(28.7 \%)$ & $381(23.1 \%)$ \\
\hline Not known & $11(12.2 \%)$ & $29(10.9 \%)$ & $67(15.1 \%)$ & $38(4.5 \%)$ & $146(8.9 \%)$ \\
\hline Total & $90(100 \%)$ & $267(100 \%)$ & $443(100 \%)$ & $840(100 \%)$ & $1649(100 \%)$ \\
\hline \multicolumn{6}{|c|}{ Hearing disability: } \\
\hline None/mild & $71(78.9 \%)$ & $245(91.8 \%)$ & $408(92.1 \%)$ & $789(93.9 \%)$ & $1520(92.2 \%)$ \\
\hline Moderate & $5(5.6 \%)$ & $3(1.1 \%)$ & $3(0.7 \%)$ & $5(0.6 \%)$ & $16(1.0 \%)$ \\
\hline Severe & $9(10.0 \%)$ & $5(1.9 \%)$ & $5(1.1 \%)$ & $12(1.4 \%)$ & $31(1.9 \%)$ \\
\hline Not known & $5(5.6 \%)$ & $14(5.2 \%)$ & $27(6.1 \%)$ & $34(4.0 \%)$ & $82(5.0 \%)$ \\
\hline Total & $90(100 \%)$ & $267(100 \%)$ & $443(100 \%)$ & $840(100 \%)$ & $1649(100 \%)$ \\
\hline \multicolumn{6}{|c|}{ Visual disability: } \\
\hline None/mild & $56(62.2 \%)$ & $193(72.3 \%)$ & $293(66.1 \%)$ & $598(71.2 \%)$ & $1145(69.4 \%)$ \\
\hline Moderate & $14(15.6 \%)$ & $41(15.4 \%)$ & $80(18.1 \%)$ & $106(12.6 \%)$ & $241(14.6 \%)$ \\
\hline Severe & $14(15.6 \%)$ & $16(6.0 \%)$ & $38(8.6 \%)$ & $77(9.2 \%)$ & $146(8.9 \%)$ \\
\hline Not known & $6(6.7 \%)$ & $17(6.4 \%)$ & $32(7.2 \%)$ & $59(7.0 \%)$ & $117(7.1 \%)$ \\
\hline Total & $90(100 \%)$ & $267(100 \%)$ & $443(100 \%)$ & $840(100 \%)$ & $1649(100 \%)$ \\
\hline
\end{tabular}

^Includes nine cases in whom the birthweight was not recorded 


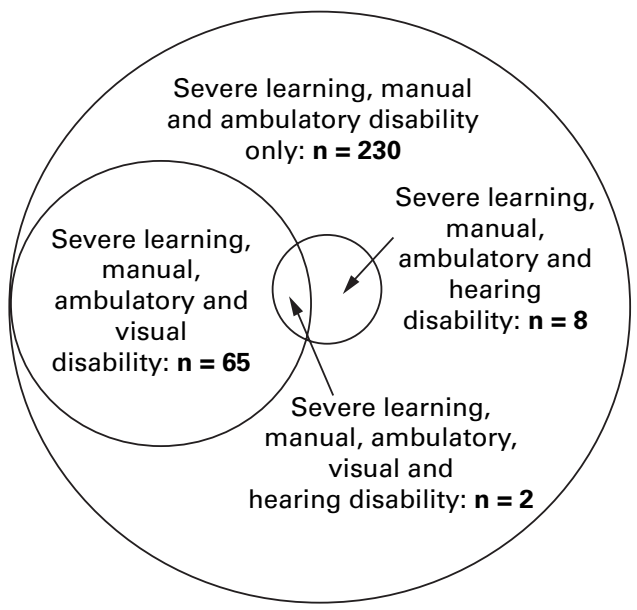

Figure 1 All birthweights: severe learning, manual, and ambulatory disability $(n=305)$.

the $95 \%$ confidence interval of each annual estimate was wide and the annual prevalence rates did not differ significantly.

In contrast to the stability of the birthweight specific cerebral palsy prevalence over the 6 year study period, the birthweight specific neonatal mortalities all showed a significant decline, ranging from $14 \%$ in infants of birthweight $<1000 \mathrm{~g}$ to $29 \%$ in those weighing $\geqslant 2500 \mathrm{~g}$.

In 20 cases there was no record of the clinical type of cerebral palsy. These were because the infant died with a diagnosis of cerebral palsy recorded but with no information on the type. Quadriplegia comprised almost two fifths and hemiplegia almost one third of the remaining 1629 cases (table 2). The type of cerebral palsy differed significantly among the different birthweight groups $\left(\chi^{2}, 9 \mathrm{df}=121.9\right.$ : $\mathrm{p}<0.0001)$. This was mainly attributable to relatively fewer cases of diplegia in the smallest and the largest birthweight groups.

Table 3 shows the severity of the motor, learning, and sensory disabilities. After excluding those of unknown severity, about a third of the children, irrespective of birthweight, are unable to walk independently. Of the heaviest infants, a significantly greater proportion have severe manual disability compared with those $<2500 \mathrm{~g}(226 / 813$ (27.8\%) vs 163/779 (20.9); $\mathrm{p}<0.001)$; they also have the highest proportion with severe learning difficulty. In the birthweight group $\geqslant 2500 \mathrm{~g}, 31.3 \%$ have a severe learning difficulty compared with $19.2 \%$ in those infants weighing $<2500 \mathrm{~g}$. This difference is highly significant $(p<0.001)$.

In contrast to the motor and learning disabilities, the sensory disabilities are more severe in those of lower birthweight. After excluding those children whose severity of hearing disability is not known, $10.2 \%$ of infants weighing $<1000 \mathrm{~g}$ have severe hearing disability compared with $1.4 \%$ of the remainder $(p<0.001)$. For severe visual disability, the respective proportions are $16.1 \%$ and $9.5 \%$ $(\mathrm{p}<0.05)$.

Of the 1649 cases of cerebral palsy, complete data on the level of disability in all five functional categories-learning, manual, am- bulatory, hearing and visual disability - was available in $1338(81 \%)$. Of these, $230(17 \%)$ had severe learning, manual, and ambulatory disability, but their vision and hearing were not severely affected. An additional eight (0.6\%) also had a severe hearing disability and $65(5 \%)$ had co-existent severe visual disability. Two children $(0.1 \%)$ were severely affected in all functional disability categories. These data are shown as a Venn diagram (fig 1).

\section{Discussion}

The stability of the birthweight specific cerebral palsy prevalence contrasts with that reported from other studies which have drawn attention to the increasing prevalence among those of the lower birthweight groups..$^{5-8}$ This could be because the prevalence rates have reached a plateau or that the period covered by the study was too short to reveal a trend that is distinct over and above random variation. Alternatively, if there was incomplete ascertainment, it would affect the more recent rather than the earlier years of the study, particularly those children least severely affected in whom the diagnosis is most likely to be delayed. As several years have elapsed since the end of the reported study period, it is unlikely that failure of ascertainment would have had more than a marginal effect.

The birthweight specific prevalence of cerebral palsy shows a sharp rise with decreasing birthweight, with the highest prevalence in the lowest birthweight group $(<1000 \mathrm{~g})$. This is in contrast to previously reported series in which the prevalence of cerebral palsy in infants $<1000 \mathrm{~g}$ was less than that in the 1000-1499 g group. In the past this would have been attributed to an artefact of the poor survival of the lowest birthweight group of infants who died before the diagnosis of cerebral palsy was made. But as survival improves, there is sufficient time for cerebral palsy to be diagnosed and counted so that the prevalence in those $<1000 \mathrm{~g}$ now exceeds that in the 1000-1499 g group.

It has long been recognised, however, that heavier infants tend to have more severe cognitive and motor disabilities than those of low birthweight. Indeed, the higher prevalence of severe learning disability among infants of normal birthweight $(\geqslant 2500 \mathrm{~g})$ compared with those of $<2500 \mathrm{~g}$ was considered to indicate a difference in the aetiology of cerebral palsy. ${ }^{13}$ An alternative explanation is the bias introduced as a result of differential survival. Among normal birthweight infants, even those with extensive cerebral damage may now survive; the neonatal mortality in this birthweight group was 1.2 per 1000 live births in $1992 .{ }^{14}$ In the lowest birthweight groups the neonatal mortality is much greater and infants with cerebral palsy would be more likely to die than unimpaired infants. The corollary to this is that, as survival in those of very low birthweight further improves, there will be a higher prevalence of cerebral palsy among the survivors.

In contrast to the higher proportion with severe cognitive and motor disability among 
the heavier infants, the severest sensory disabilities of hearing and vision are more common in the lowest birthweight group. This cannot be due to bias attributable to differential survival and is, therefore, more likely to be directly associated with preterm delivery. Retinopathy of prematurity accounts for some, but not all, of the excess of severe visual disability.

About one in five children has severe multiple disability; the clinical and social impact is considerable because most require continuous care. On a more positive note, about half of these children are not intellectually impaired. Nevertheless, these children do need appropriate educational provision to help maximise their potential despite their physical disabilities.

Controlled trials have shown the effectiveness of surfactant ${ }^{15}$ and antenatal steroid use $\mathrm{e}^{16}$ in reducing mortality and morbidity associated with hyaline membrane disease. The major impact of these interventions should be seen in cohorts born in the late 1980s and early 1990s, and their effects on cerebral palsy rates should continue to be monitored. Birthweight specific neonatal and postneonatal mortality is measured and published routinely in the United Kingdom but there is, as yet, no routine recording of disability, such that national trends in the prevalence of disability can be monitored. As long as this continues, cerebral palsy registers provide one source of information on long term disability in childhood. Not only should rates of disability be followed up but the prevalence of the various grades of severity of disability needs to be recorded if monitoring is to be comprehensive and if there is to be rational planning for the needs of the disabled.

1 Johnson A. Use of registers in child health. Arch Dis Child 1995;72:474-7.

2 Alberman E. Stillbirths and neonatal mortality in England and Wales by birthweight 1953-71. Health Trends 1974;6:14-17.

3 Pharoah POD, Alberman ED. Mortality of low birthweight infants in England and Wales 1953 to 1979. Arch Dis Child 1981;56:86-9.

4 Platt MJ, Pharoah POD. Child health statistical review, 1995. Arch Dis Child 1995;73:541-8.

5 Hagberg B, Hagberg G, Olow I. The changing panorama of cerebral palsy in Sweden. IV. Epidemiological trends

6 Hagberg B, Hagberg G, Olow I. The changing panorama of cerebral palsy in Sweden. VI. Prevalence and origin during the birth year period 1979-86. Acta Paediatrica Scandanavica 1993;82:387-93.

7 Stanley FJ, Watson L. Trends in perinatal mortality and cerebral palsy in Western Australia, 1967 to 1985 . BMf 1992;304:1658-62.

8 Pharoah POD, Cooke T, Cooke RWI, Rosenbloom L. Birthweight specific trends in cerebral palsy. Arch Dis Child 1990;65:602-6.

9 Johnson A, King R. A regional register of early childhood impairments: a discussion paper. 7 Public Health Med 1989;11:352-63.

10 Mutch L, Ronald E. The Scottish register of children with a motor deficit of central origin 1990-1992. Report to the Office of the Chief Scientist. Edinburgh: The Scottish Office, 1992.

11 Evans P, Johnson A, Mutch L, Alberman E. A standard form for recording clinical findings in children with a deficit of central origin. Dev Med Child Neurol 1989;31:119-27.

12 Griffiths R. The abilities of young children. Henley on Thames: The Test Agency Ltd, 1984.

13 Childs B, Evans PR. Birthweights of children with cerebral palsy. Lancet $1954 ; \mathbf{i}: 642-5$.

14 Office of Population, Censuses and Surveys. Mortality statistics (England \& Wales): perinatal and infant, 1992. Series tics (England \& Wales): perinatal and
DH3 No 26. London, HMSO: 1995

15 The Osiris collaborative group. Early versus delayed neonatal administration of a synthetic surfactant - the judgement of Osiris. Lancet 1992;340:1363-9.

16 Crowley P. Promoting pulmonary maturity. In: Chalmers I, Enkin M, Keirse MJSE, eds. Effective Care in Pregnancy and Childbirth. Oxford: Oxford University Press, 1989. 